\title{
Alcohol use and problem drinking in South Africa: findings from a national population-based survey
}

\author{
K Peltzer1,2, A Davids'1, P Njuho' \\ 'Social Aspect of HIV/AIDS and Health, Human Sciences Research Council, Pretoria, South Africa \\ 2Department of Psychology, University of the Free State, Bloemfontein, South Africa
}

\begin{abstract}
Objective: This study formed part of the South African National HIV, Incidence, Behaviour and Communication (SABSSM) 2008 survey, which included questions assessing the extent of alcohol use and problem drinking among South Africans. Method: A multistage random population sample of 15828 persons aged 15 or older (56.3\% women) was included in the survey. Alcohol use was assessed using the Alcohol Use Identification Test (AUDIT). Tabulation of data for different age groups, geolocality, educational level, income, and population group produced the estimates and associated confidence intervals. The odds ratios for these variables in relation to hazardous or harmful drinking were also computed. Results: Current alcohol use was reported by $41.5 \%$ of the men and $17.1 \%$ of women. White men (69.8\%) were most likely and Indian/Asian women (15.2\%) least likely to be current drinkers. Urban residents (33.4\%) were more likely than rural dwellers (18.3\%) to report current drinking. Risky or hazardous or harmful drinking was reported by 9\%: 17\% among men and 2.9\% among women. In men, risky drinking was associated with: the 20-54 year age group; the Coloured population group; lower economic status; and lower education. Among women, risky drinking was associated with: urban residence; the Coloured population group; lower education; and higher income. Conclusion: An increase in current, binge drinking and hazardous or harmful drinking prevalence rates was observed from 2005 to 2008 in South Africa. Multilevel interventions are required to target high-risk drinkers and to create awareness in the general population of the problems associated with harmful drinking. Future prospective studies are needed to assess the impact of problem drinking.
\end{abstract}

Key words: Alcohol use; Binge drinking; Hazardous or harmful drinking; Prevalence; National, population-based survey; South Africa

Received: 07-11-2009

Accepted: 03-05-2010

\section{Introduction}

Globally, the net effect of alcohol consumption on health is detrimental, with an estimated 3.8\% of all global deaths and $4.6 \%$ of global disability-adjusted life-years (DALYs) attributable to alcohol. ${ }^{1}$ In South Africa the estimated burden of disease attributable to alcohol use in 2000 was 7.1\% (95\% CI $6.6-7.5 \%)$ of all deaths and $7.0 \%$ (95\% CI 6.6 - 7.4\%) of total DALYs. In terms of alcohol-attributable disability, alcohol use disorders ranked first (44.6\%), interpersonal violence second (23.2\%), and foetal alcohol syndrome (FAS) third (18.1\%). ${ }^{2}$

How alcohol is consumed in a country or within a group (i.e., pattern of drinking) is an important determinant of types and levels of problems associated with drinking. Alcohol consumption should be

\section{Correspondence:}

Prof. K Peltzer

Social Aspect of HIV/AIDS and Health, Human Sciences Research

Council, Pretoria, South Africa

email: kpeltzer@hsrc.ac.za understood in the context of patterns of drinking and these vary a great deal between societies. In much of the developing world, the predominant pattern is of infrequent heavy drinking, particularly by men. Specifically, this is determined by some of the indicators used in determining drinking pattern: number of heavy drinking occasions; high usual quantity of alcohol consumed; drinking in public places; and drinking at community festivals. ${ }^{3}$ Many of the developing subregions are characterized by hazardous drinking patterns. ${ }^{4}$ Hazardous drinking is defined as a quantity or pattern of alcohol consumption that places patients at risk for adverse health events, while harmful drinking is defined as alcohol consumption that results in adverse events (e.g., physical or psychological harm). ${ }^{5}$

Population surveys provide evidence of drinking patterns at the individual level. Few representative and population-based surveys of alcohol consumption have been conducted in South Africa and these include two Demographic and Health Surveys (DHS) of 1998 and $2003^{6-7}$, the South Africa World Health Survey ${ }^{1}$ (WHS) of 2003', the South African Stress and Health (SASH) survey of 2002-20049 and the 
South African national HIV prevalence, Behaviour and Communication Survey (SABSSM II) of 2005. ${ }^{10}$ Based on data from the 2002-2004 South African Stress and Health study (using the World Health Organization Composite International Diagnostic Interview (CIDI)), Van Heerden et al..$^{9}$ found a cumulative occurrence of alcohol use of $38.7 \%$. There were significant associations between male gender and alcohol; and Coloureds and Whites were more likely than Black Africans to have used alcohol. Use of alcohol was much more common in recent cohorts, with a similar cumulative incidence of alcohol use across age cohorts. Prevalence rates of current drinking (past week or past month) are similar across different surveys, ranging from 20-30\% (28\% DHS 1998; 20\% DHS 2003; 29.9\% WHS 2003; and 24.5\% SABSSM II 2005) with significantly higher rates among men than women. In terms of binge drinking (defined as drinking five or more alcohol drinks on the same occasion on at least 1 day in the past 30 days or 7 days) $7.4 \%$ prevalence was found in SABSSM II 2005 and 10.8\% in WHS 2003. With regard to hazardous or harmful drinking, 17.2\% prevalence was reported in DHS 1998 and 13.7\% in DHS 2003 (measured with the CAGE - named for an acronym of its four questions); while 6.2\% was reported in SABSSM II 2005 (measured with the Alcohol Use Disorders Identification Test (AUDIT)). The first and only national school survey (Youth Risk and Behaviour Survey) was conducted in 2002 and this reported that $31.8 \%$ of learners (78.7\% were between the ages of 14 and 18 years) were current alcohol users, while 23.0\% had been binge drinking (five or more drinks) in the past month in South Africa. ${ }^{11}$

Alcohol problem drinking patterns (either binge drinking or hazardous or harmful drinking) vary according to age, social class, occupation, school status, gender and geographic location. ${ }^{12}$ Regarding educational level, in both the DHS 1998 and SABSSM II 2005, lower levels of education were associated with higher levels of binge drinking among current drinkers. The most prevalent age for binge drinking in South Africa is between 18 and 35 years of age. Higher binge drinking levels were found in urban compared with rural areas among men in SABSSM II 2005 (17\% versus 1 1\% respectively) and in the WHS 2003 (12\% versus 9\% respectively). ${ }^{10}$ Regarding ethnic group, in SABSSM II 2005, binge drinking among men was highest among Coloureds (23\%), followed by Whites (16\%), Black African (13\%) and Indian/Asian (7\%). ${ }^{10}$ The correlates of binge or heavy drinking, based on American and Canadian studies, include being male, young (i.e. age 21-25 years), unmarried, lower educational attainment and unemployed. ${ }^{13,14}$ In European studies, the correlates are similar except that heavy drinking in men is more prevalent in middle age (30.s to 50s). ${ }^{15,16}$

As there is a need for accurate recent national prevalence data on adolescent and adult alcohol use and problem drinking in South Africa, the aim of this secondary analysis is to provide current data that could assist in the development and implementation of effective alcohol use policies and intervention programmes aimed at these populations in South Africa.

\section{Method}

\section{Sample and procedure}

The survey targeted all persons over 2 years of age living in South Africa and residing in homes (i.e. excluding individuals living in educational institutions, old-age homes, hospitals and uniformed service barracks but including those living in hostels.) A multi-stage cluster stratified sample stratified by province, settlement geography (geotype) and predominant population group in each area was used. A systematic sample of 15 households was drawn from each of 1000 census enumeration areas (EAs). In each household, one person was randomly selected in each of four mutually exclusive age groups (under 2 years; 2-14 years; 15-24 years; 25+ years). The sample used in this analysis includes the age group 15 years and above; sample $=13828$ (77.5\% Black Africans, 9.1\% Coloureds, 10.5\% Whites and $2.8 \%$ Indians/Asians). The South African population falls mainly into four racially defined social groups: black Africans, whites, coloureds (derived from Asian, European, and Khoisan and other African ancestry) and Asians (mainly Indians). Although defining social groups by race has its disadvantages as these groups do not have anthropological or scientific validity, it is useful because there are important differences between the groups for many indicators of health. These differences are mediated by cultural, political, and economic factors. Socio-demographic and behavioural information was collected with questionnaires administered by trained fieldworkers (more details on the methodology are described by Shisana et al. $\left.{ }^{17}\right)$.

\section{Measure}

Alcohol use: was assessed using the Alcohol Use Disorders Identification Test (AUDIT). The AUDIT is a measure of the prevalence of alcohol use. ${ }^{18}$ The AUDIT's 10 items cover the three conceptual domains of consumption, dependence symptoms, and alcoholrelated consequences that were intended to parallel the World Health Organization concepts of hazardous drinking, alcohol dependence, and alcohol-related harm. Because AUDIT is reported to be less sensitive at identifying risk drinking in females ${ }^{19}$, the cut-off point of binge drinking for females (4) was reduced by one unit as compared with males (5). The AUDIT is currently the only instrument specifically designed to identify hazardous and harmful drinking and is valid for detecting heavy drinking also in a general population sample. ${ }^{20}$ Cronbach alpha for the AUDIT was 0.84 for this sample. Furthermore, an assessment of alcohol use using a cut-off score of 8 or more was made for hazardous or harmful drinking. Hazardous drinking is defined as a quantity or pattern of alcohol consumption that places patients at risk for adverse health events, while harmful drinking is defined as alcohol consumption that results in adverse events (e.g. physical or psychological harm).

\section{Data analysis}

Data analysis was performed using STATA software version 10.0 (Stata Corporation, College Station, Texas, USA). The analysis in STATA took into account the multilevel stratified cluster sample design of the study. The estimates of prevalence of alcohol use variables and associated two-sided 95\% confidence intervals are reported. The pvalue less or equal to 5\% is used to indicate statistical significance. A test of two proportions is considered statistically significant if the two confidence intervals associated with the associated estimates do not overlap. The estimates, 95\% confidence intervals and the p-value are adjusted for the multi-stage stratified cluster sample design of the study. We also conducted adjusted logistic regression analysis to calculate adjusted odds ratios and 95\% confidence intervals for men and for women separately for hazardous or harmful drinking (AUDIT score 8 or more) in relation to sociodemographic variables.

\section{Results}

\section{Sample characteristics}

From the total sample of 13828 , the individual interview response rate was $89.1 \%$. The socio-demographic characteristics of the weighted sample closely match those of the population estimates in terms of sex, race, and province indicating that the 2008 survey sample is representative of the population from which it was drawn. ${ }^{17}$ The 
majority of the respondents were between the ages of 25 to 34 and 35 to 44 years old (23.6\% and $18.1 \%$ respectively). With regard to the locality type, two-thirds (62.5\%) of the respondents were located in urban areas (which includes urban-formal and urban informal areas.) In terms of Province, the highest proportion of respondents was from Gauteng (21.1\%) followed by KwaZulu-Natal (20.2\%.) More than half of the participants (59.6\%) had Grade 8 or more education, whilst 9.8\% had no formal education. As for employment and income status, whilst $21.8 \%$ of the sample reported to be unemployed at the time of the survey, a higher proportion of respondents (27.5\%) earned less than R12 000 per year (R1000.00 per month) and only $24.6 \%$ of the respondents earned between R12 001 - R48 000 per year (R4000.00 per month). There was also a definite gender difference with regard to income status. Men earned more than their women counterparts, whether looking at salaries between R12 001 and R48 000 per year (men 28.5\% and women 20.6\%) or salaries earned over R48 001 per year (men 28.9\% and women 23.1\%) (Table I).

\section{Frequency of alcohol use}

From the total participants, $41.5 \%$ of the men and $17.1 \%$ of the women 15 years and older reported that they were currently (past month) consuming alcohol; for both sexes, the rate was 27.7\%. On the other hand abstention rates were high: $72.3 \%$ in the whole sample and $82.9 \%$ among females and 58.5\% among males. The overall prevalence of binge drinking and hazardous or harmful drinking was 9.6\% and 9.0\%, respectively. Among current drinkers, the prevalence of hazardous or harmful drinking was 31.5\% (95\% CI: 29.3-33.7), and among males 39.4\% (95\% CI: 36.5-42.4) and females 16.6\% (95\% CI: 13.7-19.5). Results indicated that current drinking rates, binge drinking and hazardous or harmful drinking differed by age, sex, population group, locality type, province, education, employment and income status. Highest levels of current drinking were reported by white men (69.8\%), followed by white women (61.7\%) and Coloured men (57.4\%) and the lowest rates by Black African and

\section{Table I: Demographic characteristics of respondents 15 years and older}

\begin{tabular}{|c|c|c|c|c|c|c|}
\hline & $\begin{array}{l}\text { Men }(n=5501) \\
(43.7 \%)\end{array}$ & Weighted & $\begin{array}{l}\text { Women }(n=8327) \\
(56.3 \%)\end{array}$ & Weighted & Total $(n=13828)$ & Weighted \\
\hline & $N$ & & $\%[95 \% \mathrm{Cl}]$ & $N$ & $\%[95 \% \mathrm{Cl}]$ & N \% [95\%Cl] \\
\hline \multicolumn{7}{|l|}{ Age } \\
\hline $15-19$ & 1211 & 19.5 [18.0-21.0] & 1235 & 12.6[11.7-13.5] & 2446 & $15.6[14.8-16.4]$ \\
\hline $20-24$ & 904 & $15.7[14.3-17.3]$ & 1230 & $13.5[12.5-14.6]$ & 2134 & $14.5[13.6-15.4]$ \\
\hline $25-34$ & 923 & $22.1[20.2-24.2]$ & 1391 & $24.7[23.2-26.3]$ & 2314 & $23.6[22.4-24.9]$ \\
\hline $35-44$ & 820 & $16.0[14.4-17.7]$ & 1546 & $19.7[18.4-21.0]$ & 2366 & $18.1[17.1-19.1]$ \\
\hline $45-54$ & 786 & $13.4[12.2-14.7]$ & 1271 & $12.5[11.5-13.6]$ & 2057 & $12.9[12.1-13.7]$ \\
\hline $55-64$ & 464 & $6.9[6.1-7.8]$ & 855 & $8.4[7.6-9.3]$ & 1319 & $7.7[7.2-8.4]$ \\
\hline $65+$ & 393 & $6.4[5.6-7.3]$ & 799 & $8.6[7.7-9.5]$ & 1192 & 7.6[7.0-8.3] \\
\hline \multicolumn{7}{|l|}{ Locality type } \\
\hline Urban & 4068 & $64.5[60.6-68.2]$ & 5883 & 61.0[56.9-64.8] & 9951 & $62.5[58.8-66.1]$ \\
\hline Rural & 1433 & $35.5[31.8-39.4]$ & 2444 & $39.0[35.2-43.1]$ & 3877 & $37.5[33.9-41.2]$ \\
\hline \multicolumn{7}{|l|}{ Province } \\
\hline Western Cape & 802 & $12.7[11.2-14.3]$ & 1004 & $10.4[9.2-11.7]$ & 1806 & $11.4[10.2-12.7]$ \\
\hline Eastern Cape & 714 & $13.3[11.4-15.5]$ & 1092 & $12.8[11.1-14.8]$ & 1806 & $13.0[11.4-14.8]$ \\
\hline Northern Cape & 445 & $2.2[1.8-2.6]$ & 593 & $1.9[1.7-2.2]$ & 1038 & $2.0[1.8-2.3]$ \\
\hline Free State & 358 & $6.5[5.1-8.1]$ & 571 & 5.8[4.8-6.9] & 929 & $6.1[5.0-7.3]$ \\
\hline KwaZulu-Natal & 976 & $16.3[14.0-19.0]$ & 1690 & $23.1[20.2-26.4]$ & 2666 & $20.2[17.7-22.8]$ \\
\hline North-West & 437 & $8.5[7.3-10.0]$ & 670 & $8.2[7.1-9.5]$ & 1107 & $8.3[7.3-9.5]$ \\
\hline Gauteng & 855 & $22.6[19.2-26.4]$ & 1304 & $20.0[17.3-23.1]$ & 2159 & $21.1[18.3-24.3]$ \\
\hline Mpumalanga & 439 & $7.1[5.9-8.6]$ & 641 & $7.1[5.9-8.4]$ & 1080 & $7.1[6.0-8.4]$ \\
\hline Limpopo & 475 & $10.8[9.3-12.5]$ & 762 & $10.7[9.3-12.4]$ & 1237 & $10.7[9.5-12.2]$ \\
\hline \multicolumn{7}{|l|}{ Population group } \\
\hline Black African & 3149 & $75.5[72.8-78.1]$ & 5148 & $79.1[76.7-81.3]$ & 8297 & $77.5[75.2-79.7]$ \\
\hline White & 703 & $11.4[9.6-13.4]$ & 942 & $9.8[8.3-11.5]$ & 1645 & $10.5[9.0-12.1]$ \\
\hline Coloured & 1070 & $10.2[8.8-11.8]$ & 1436 & $8.2[7.1-9.4]$ & 2506 & $9.1[7.9-10.3]$ \\
\hline Indian or Asian & 566 & $2.8[2.1-3.6]$ & 786 & $2.8[2.1-3.8]$ & 1352 & $2.8[2.1-3.6]$ \\
\hline Others & 13 & $0.1[0.1-0.3]$ & 15 & $0.2[0.1-0.3]$ & 28 & $0.1[0.1-0.2]$ \\
\hline \multicolumn{7}{|l|}{ Education } \\
\hline No education & 427 & 7.8[6.8-8.9] & 928 & $11.3[10.2-12.5]$ & 1355 & $9.8[8.9-10.7]$ \\
\hline Grades 1 to 5 & 752 & $15.7[14.3-17.2]$ & 1228 & $14.2[13.1-15.3]$ & 1980 & $14.8[13.9-15.8]$ \\
\hline Grades 6 to 7 & 910 & $16.2[14.9-17.6]$ & 1274 & $15.4[14.3-16.7]$ & 2184 & $15.7[14.8-16.7]$ \\
\hline Grades 8 to 11 & 2913 & $52.0[49.7-54.2]$ & 4221 & $52.3[50.3-54.3]$ & 7134 & $52.1[50.4-53.8]$ \\
\hline Grade 12 & 154 & $2.6[2.0-3.3]$ & 189 & $2.0[1.6-2.6]$ & 343 & $2.3[1.9-2.8]$ \\
\hline Higher & 345 & $5.8[4.7-7.2]$ & 487 & $4.8[3.9-5.9]$ & 832 & $5.2[4.3-6.3]$ \\
\hline \multicolumn{7}{|l|}{ Employment status/income } \\
\hline Not employed & 454 & $17.1[14.8-19.6]$ & 832 & 26.7[23.8-29.8] & 1286 & $21.8[19.8-24.1]$ \\
\hline Less than R12 000 per year & 683 & $25.5[22.9-28.4]$ & 990 & $29.6[27.0-32.3]$ & 1673 & $27.5[25.6-29.6]$ \\
\hline R12 001 - R48 000 per year & 804 & $28.5[25.8-31.4]$ & 752 & $20.6[18.3-23.2]$ & 1556 & $24.6[22.7-26.6]$ \\
\hline More than R48 001 per year & 956 & $28.9[26.0-32.1]$ & 851 & $23.1[20.4-26.1]$ & 1807 & $26.0[23.7-28.6]$ \\
\hline
\end{tabular}




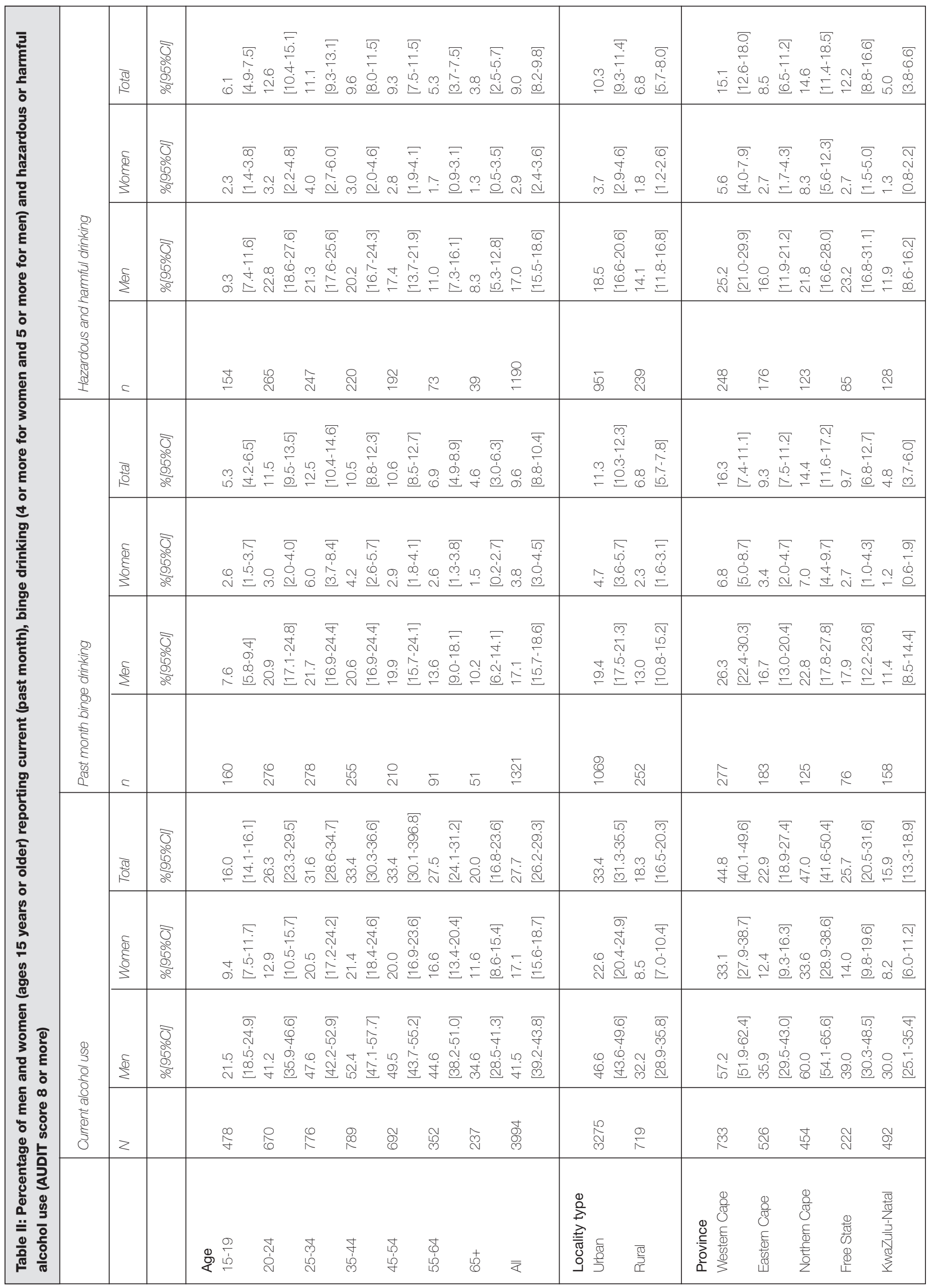




\section{Table II continued}

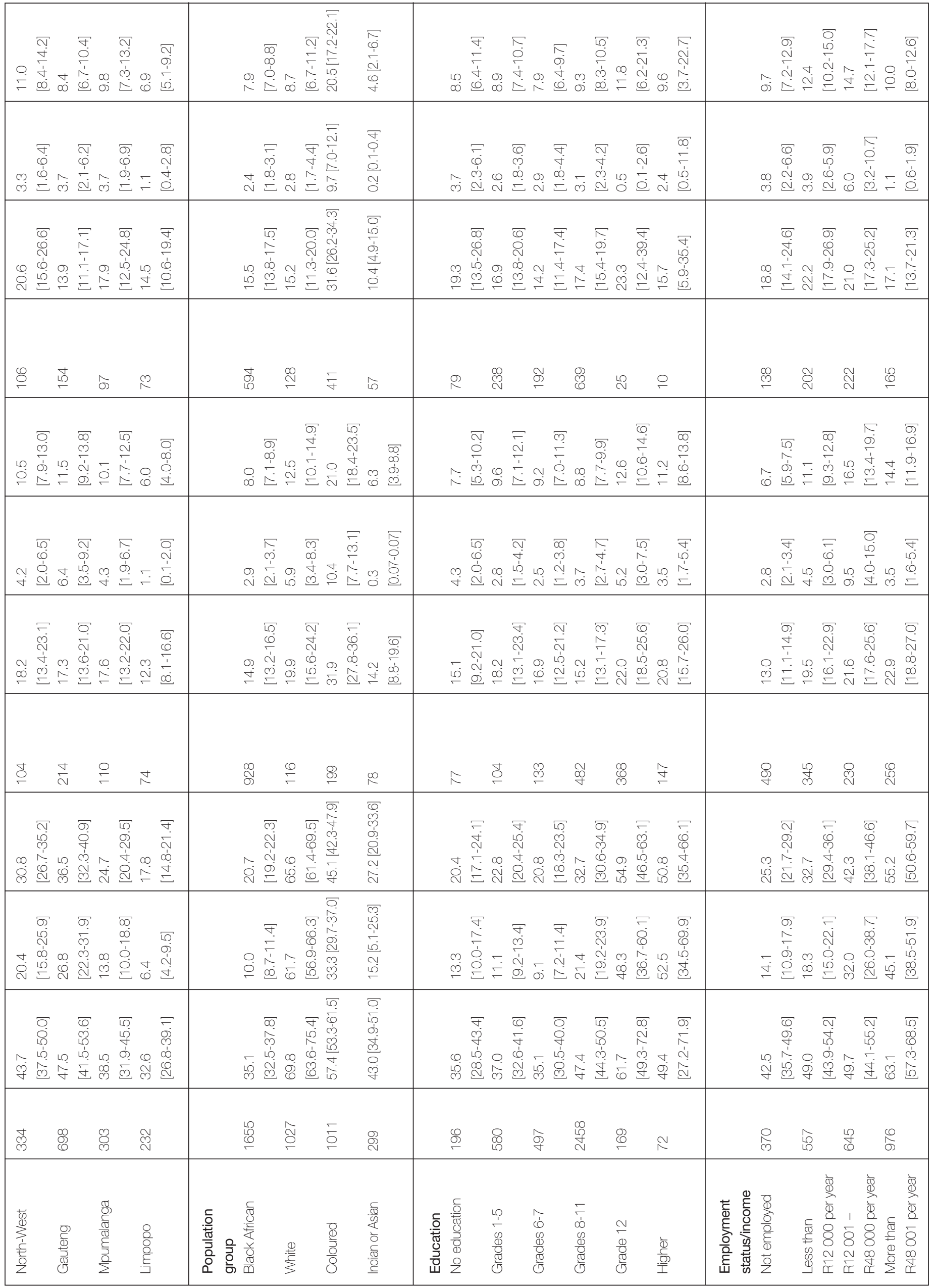


Asian women (10.0\% and 15.2\%, respectively). Binge drinking and hazardous or harmful drinking was highest in men among Coloureds (31.9\% and 31.6\%, respectively) and in women also among Coloureds (10.4\% and 9.7\%, respectively), followed by white men for binge drinking (19.9\%) and Black African and White men for hazardous or harmful drinking (15.5\% and 15.2\%, respectively). For both men and women, the highest levels of current alcohol use were among persons in the 35 to 44 and 45 to 54 age groups (33.4\%); the lowest levels were in the 15 to 19 and 65 years and above age groups (16 and 20\%, respectively.) For both men and women, highest levels of binge drinking (12.5\%) were in the 25 to 34 age group and, for hazardous or harmful drinking, in the 20 to 24 year-old age group (12.6\%). Hazardous or harmful alcohol use was significantly higher in men (17\%) than women (2.9\%). For both men and women, higher rates of alcohol use (current use, binge drinking and hazardous or harmful drinking) were recorded in urban (rather than rural) areas. In both sexes, the highest current drinking, binge and hazardous or harmful drinking levels were reported in two provinces (Western Cape and Northern Cape). There were more current drinkers (male and female) in higher educational groups of Grade 12 and higher (more than 50\%) than in lower educational groups from no education to Grade 11 (below 33\%). Likewise, the proportion of current drinkers and binge drinkers increased with increasing income (from not employed: $25.3 \%$ and $6.7 \%$ respectively; to more than 48001 Rand a year income: $55.2 \%$ and $14.4 \%$, respectively). However, for hazardous or harmful drinking, similar prevalence rates were observed across educational, employment and income levels (Table II).

\section{Multivariate logistic regression with hazardous or harmful alcohol use}

Hazardous or harmful drinking was significantly greater for men in the 20 to 24,25 to 34,35 to 44 and 45 to 54 year age groups compared with men ages 15 to 19 years, while among women hazardous or harmful drinking did not differ across age groups. Urban residence was for women, but not for men, associated with hazardous or harmful drinking. With regard to population group, Coloured men had significantly higher rates of hazardous or harmful drinking than Black African men, while among women hazardous or harmful drinking was lower for Indians or Asians and higher for Coloureds compared with Black Africans. A lack of education in women was associated with hazardous or harmful drinking, while men with Grades 6 to 11 education were adversely associated with hazardous or harmful drinking. Among men, low income was associated with hazardous or harmful drinking; whereas for women higher income was "protective" from hazardous or harmful drinking (Table III).

\section{Table III: Logistic regression analysis of sociodemographic characteristics and hazardous or harmful alcohol use for 15 years} and older

\begin{tabular}{|c|c|c|c|c|c|c|}
\hline & \multicolumn{3}{|c|}{ Men [Pseudo R².05] } & \multicolumn{3}{|c|}{ Women [Pseudo R2.08] } \\
\hline & $A O R$ & $95 \% \mathrm{Cl}$ & $P$ & $A O R$ & $95 \% \mathrm{Cl}$ & $P$ \\
\hline \multicolumn{7}{|l|}{ Age } \\
\hline 15-19 & 1.00 & & & 1.00 & & \\
\hline $20-24$ & 2.59 & $1.81-3.70$ & .000 & 1.52 & $0.77-2.97$ & .224 \\
\hline $25-34$ & 2.27 & $1.56-3.31$ & .000 & 1.94 & $0.99-3.79$ & .054 \\
\hline $35-44$ & 1.89 & $1.27-2.82$ & .002 & 1.22 & $0.61-2.44$ & .567 \\
\hline $45-54$ & 1.66 & $1.11-2.48$ & .014 & 0.97 & $0.49-1.94$ & .938 \\
\hline $55-64$ & 0.93 & $0.54-1.60$ & .786 & 0.55 & $0.23-1.27$ & .162 \\
\hline $65+$ & 0.65 & $0.35-1.21$ & .174 & 0.35 & $0.12-1.04$ & .058 \\
\hline \multicolumn{7}{|l|}{ Geolocality } \\
\hline Urban & 1.00 & & & 1.00 & & \\
\hline Rural & 0.80 & $0.63-1.04$ & .094 & 0.56 & $0.36-0.86$ & .009 \\
\hline \multicolumn{7}{|l|}{ Population group } \\
\hline Black African & 1.00 & & & 1.00 & & \\
\hline White & 1.13 & $0.76-1.68$ & .553 & 1.89 & $0.97-3.68$ & .060 \\
\hline Coloured & 2.43 & $1.88-3.14$ & .000 & 4.03 & $2.47-6.58$ & .000 \\
\hline Indian or Asian & 0.62 & $0.33-1.18$ & .146 & 0.08 & $0.02-0.35$ & .001 \\
\hline \multicolumn{7}{|l|}{ Education } \\
\hline No education & 1.00 & & & 1.00 & & \\
\hline Grades 1-5 & 0.84 & $0.46-1.51$ & .553 & 0.25 & $0.12-0.52$ & .000 \\
\hline Grades 6-7 & 0.52 & $0.29-0.96$ & .035 & 0.34 & $0.18-0.66$ & .001 \\
\hline Grades 8-11 & 0.56 & $0.33-0.96$ & .032 & 0.31 & $0.17-0.58$ & .000 \\
\hline Grade 12 & 0.59 & $0.33-1.05$ & .071 & 0.22 & $0.10-0.45$ & .000 \\
\hline Higher & 0.69 & $0.36-1.32$ & .262 & 0.19 & $0.08-0.46$ & .000 \\
\hline \multicolumn{7}{|l|}{ Employment status/income } \\
\hline Not employed & 1.00 & & & 1.00 & & \\
\hline Less than R12 000 per year & 1.42 & $1.05-1.91$ & .022 & 1.47 & $0.96-2.27$ & .078 \\
\hline R12 001 - R48 000 per year & 1.57 & $0.83-1.61$ & .385 & 1.71 & $0.80-3.65$ & .163 \\
\hline More than R48 001 per year & 0.96 & $0.63-1.46$ & .856 & 0.36 & $0.17-0.74$ & .005 \\
\hline
\end{tabular}

Notes: $\mathrm{AOR}=$ adjusted odds ratio; $\mathrm{Cl}=$ confidence interval 


\section{Discussion}

This national study of 2008 among persons 15 years and older found that $27.7 \%$ were currently (past month) using alcohol, $41.5 \%$ for men and $17.1 \%$ for women. These rates show a slight increase over the last population-based survey of SABSSM II 2005 (overall (24.5\%) and in men (39.2\%) and women (15.7\%)). ${ }^{10}$ However, they were roughly the same in the DHS of 1998, (overall $28 \%$ and $44.6 \%$ and $16.9 \%$ current drinkers among men and women, respectively). ${ }^{21}$

This study found that overall 9.6\% of South Africans (17.1\% of men and 3.8\% of women) engaged in past month binge drinking. These rates also show a slight increase compared with the last populationbased survey of SABSSM II 2005 (overall (7.4\%) and in men (14.3\%) and women (3.2\%)). ${ }^{10}$ In relation to data from other African countries, the $9.6 \%$ of binge drinking in South Africa is lower than some African countries (Burkina Faso 1 1.6\% and Chad 11.0\%) and higher than others (e.g. Ethiopia 9.3\%, Namibia 4.1\%, Zimbabwe 2.7\%, Ghana 1.9\%). ${ }^{22}$ However, higher rates for past month binge drinking were found in two national US surveys in 2003: 14.7\% for the Behavioural Risk Factor Surveillance System (BRFSS), a telephone survey; and $21.6 \%$ in the National Survey on Drug Use and Health (NSDUH), an inperson population-based survey. ${ }^{23}$

Further, the current study found that hazardous or harmful alcohol use was 9.0\% (men 17\% and women 2.9\%.) These rates represent a considerable increase compared with the last population-based survey of SABSSM II 2005 (overall (6.2\%) and in men (12.7\%) and women (2.2\%)). 10 This is, however, still lower than in other developing countries (e.g. in Tibet 16.2\% (female: 9.6\%; male: $31.6 \%)^{24}$; in rural Vietnam $25.5 \%$ among men and $0.7 \%$ among women ${ }^{25}$; and in 16 to 25 year-old youth in Thailand $24.3 \%$ hazardous and harmful drinking ${ }^{26}$ ). It is also lower than in European Union countries (15\%) ${ }^{27}$ but similar to Sweden with $18 \%$ of men and $5 \%$ of women. ${ }^{28}$

The study found medium high abstention rates (72.3\%) and higher rates of high consumers and heavy drinkers among drinkers (31.5\%), a pattern which has also been found in several other African countries such as Burkina Faso (66.7\% and 37.1\%, respectively), Chad (73.7\% and 54.7\%), Malawi (77.8\% and 25.0\%) and Zambia (72.5\% and $23.5 \%$, respectively). ${ }^{29}$ Roerecke, et a ${ }^{30}$ note that taking into account the relatively high abstention rates, average consumption per drinker in sub-Saharan Africa (19.5 L) is among the highest in the world. The pattern of drinking in South Africa is also one with high potential for causing health or social harm. ${ }^{31}$

Hazardous or harmful drinking was significantly greater for men in the 20 to 24,25 to 34,35 to 44 and 45 to 54 year age groups compared with men ages 15 to 19 years, while among women hazardous or harmful drinking did not differ across age groups. The prevalence of binge or heavy drinking in North America is highest in young people (aged 21-25 years) ${ }^{13,14}$, while in European studies heavy drinking in men is more prevalent in middle age (30s to 50s). ${ }^{15,16}$ In this population-based survey, past month binge drinking among 15 to 19 year-olds was $7.6 \%$ in males and $2.6 \%$ in females which is much lower than that found in the same age group from the national school survey (29.3\% for males and $17.9 \%$ for females). ${ }^{11}$ These large differences may be attributed to the survey methodology, such that higher willingness to report binge drinking was found in a self-administered school setting as compared with a face-to-face interview in a household setting. The age distribution in most developing societies including South Africa is skewed towards younger populations and many of the primary effects of alcohol misuse arise from episodes of acute alcohol intoxication. ${ }^{32}$

With regard to area difference, urban residence was associated with hazardous or harmful drinking in women but not in men. As for socioeconomic differences, this study found that in concordance with other studies ${ }^{27}$, those with lower socio-economic status (SES) were more likely to abstain from alcohol or were non-current drinkers. Further, a lack of education in women was associated with hazardous or harmful drinking, while men with Grades 6 to 11 level of education were adversely associated with hazardous or harmful drinking. Among men, low income was associated with hazardous or harmful drinking, whereas among women, higher income was "protective" from hazardous or harmful drinking. Lower educational attainment and unemployment were also found to be associated with binge or heavy drinking in other studies. 13,14 Rahav, et al ${ }^{33}$ found that gender differences between countries in drinking were strongly associated with women's position in society, as well as with modernization. In a population-based survey in Botswana, higher education was associated with heavy alcohol use. ${ }^{34}$

With regard to population group, Coloureds had significantly higher rates of hazardous or harmful drinking compared with other population groups. This finding is consistent with other previous studies in South Africa. ${ }^{7}$ Research on understanding the specific cultural norms and other factors accounting for these differences may help in designing targeted intervention strategies. ${ }^{21}$

\section{Limitations}

The study had several limitations. These include a 10.9\% survey nonresponse rate and the fact that institutional populations were excluded. This was a self-reported household survey on alcohol consumption which may under-report the true consumption rate. According to Stockwell et al. ${ }^{35}$ :

\section{"Questions about typical quantities of alcohol consumed can lead to underestimates, as do questions about drinking 'standard drinks' of alcohol. Recent recall methods encourage fuller reporting of volumes plus more accurate estimates of unrecorded consumption and the proportion of total alcohol consumption that places drinkers at risk of harm. However, they do not capture longer-term drinking patterns. It is recommended that both recent recall and measures of longer- term drinking patterns are included in national surveys."}

As respondents were interviewed in a multi-component household survey, it is possible that they under-reported alcohol use, particularly in females. ${ }^{21}$ The data from the national school survey ${ }^{11}$ showed much higher rates of current alcohol use among 15 to 19 year-olds (38.5\% for males and $26.4 \%$ for females) as compared to 15 to 19 year-olds interviewed in househould surveys (25.3\% for males and 14.7\% for females in the DHS 1998; and 17.2\% for males and 8.4\% for females in the SABSSM II 2005). It appears that a computer-assisted selfinterview might improve the respondents' willingness to report alcohol use. ${ }^{23}$ Furthermore, due to different methodologies in different population-based surveys, we were unable to assess for a trend analysis over time.

\section{Conclusion}

An increase in current, binge drinking and hazardous or harmful drinking prevalence was observed from 2005 to 2008 in South Africa. For populations with high rates of hazardous alcohol use, both population-wide measures (for example, taxation on alcoholic beverages) and individual-based interventions (for example, brief health care provider advice) have been shown to have a notable impact on reducing the global burden of alcohol misuse. ${ }^{1}$ Most 
alcohol-related harm is attributable to hazardous/harmful drinkers who make disproportionate use of primary health care systems, but often go undetected and untreated for long periods, even though brief, easily delivered interventions are effective in this group of people. ${ }^{1}$ The South African health care system currently focuses on providing tertiary care services for the treatment of dependence (where there is often a poor outcome). ${ }^{36,37}$ This focus needs to shift towards the cost-effective strategy of providing brief interventions for early alcohol use disorders. Effective evidence-based combinations of psychosocial and pharmacological treatments for alcohol use disorders are available but are costly to implement. ${ }^{37}$

\section{Acknowledgements}

This study was supported by Cooperative Agreement Number U2G/PS000570-04 from Centers for Disease Control and Prevention (CDC). Its contents are solely the responsibility of the authors and do not necessarily represent the official views of the CDC

\section{References}

1. Rehm J, Mathers C, Popova S, Thavorncharoensap M, Teerawattananon Y, Patra J. Global burden of disease and injury and economic cost attributable to alcohol use and alcohol-use disorders. Lancet 2009; 373(9682): 2223-33.

2. Schneider M, Norman R, Parry C, Bradshaw D, Plüddemann: the South African Comparative Risk Assessment Collaborating Group. Estimating the burden of disease attributable to alcohol use in South Africa in 2000. South African Medical Journal 2007; 97: 664-72.

3. Obot IS. Alcohol use and related problems in Sub-Saharan Africa. African Journal of Drug and Alcohol Studies 2006; 5(1): 17-28.

4. World Health Organisation (WHO). Alcohol in developing countries: a public health approach. World Health Organisation, Geneva, 2002.

5. Reid MC, Fiellin DA, O'Connor PG. Hazardous and harmful alcohol consumption in primary care. Archives of Internal Medicine 1999; 159(15): 1681-1689.

6. Department of Health. South African Demographic and Health Survey 1998 Pretoria: Department of Health, 1998.

7. Department of Health. South Africa Demographic and Health Survey 2003. Pretoria: Department of Health, 2007.

8. Community Agency for Social Enquiry (CASE). World Health Survey 2003: Report of South Africa. Geneva: World Health Organisation, 2006.

9. Van Heerden MS, Grimsrud AT, Seedat S, Myer L, Williams DR, Stein DJ. Patterns of substance use in South Africa: results from the South African Stress and Health study. South African Medical Journal 2009; 99: 358-66.

10. Peltzer K, Ramlagan S. Alcohol use trends in South Africa. Journal of Social Science 2009; 18(1): 1-12.

11. Reddy SP, Panday S, Swart D, Jinabhai CC, Amosun SL, James S, et al. Umthenthe uhlaba usamila - The South African youth risk behaviour survey 2002. Cape Town: Medical Research Council, 2003.

12. Rueger SY, Malecki CK, Demaray MK. Relationship between multiple sources of perceived social support and psychological and academic adjustment in early adolescence: comparisons across gender. Journal of Youth and Adolescence 2008; DOI 10.1007/s10964-008-9368-6.

13. U.S. Department of Health and Human Services, Substance Abuse and Mental Health Services Administration, Office of Applied Studies. National Household Survey on Drug Abuse: 2001. Washington, DC: US DHHS, 2002

14. Naimi TS, Brewer RD, Mokdad A, Denny C, Serdula MK, Marks JS. Binge drinking among US adults. JAMA 2003; 289: 70-75.

15. Mateos R, Páramo M, Carrera I, Rodríguez-López A. Alcohol consumption in a southern European region (Galicia, Spain). Substance Use and Misuse 2002; 37: 1957-1976.

16. Meyer C, Rumpf HJ, Hapke U, Dilling H, John U. Prevalence of alcohol consumption, abuse and dependence in a country with high per capita consumption: findings from the German TACOS study. Social Psychiatry and Psychiatric Epidemiology 2000; 35(12): 539-47.

17. Shisana O, Rehle T, Simbayi LC, Zuma K, Jooste S, Pillay-van-WykV, et al and the SABSSM III Implementation Team. South African national HIV prevalence, incidence, behaviour and communication survey 2008: A turning tide among teenagers? Cape Town: HSRC Press, 2009.

18. Babor TF, Higgens-Biddle JC, Saunders JB, Monteiro MG. AUDIT: The Alcohol Use Disorders Identification Test. Guidelines for use in primary care. World Health Organization, Geneva, Department of Mental Health and Substance Dependence, 2001

19. Freeborn DK, Polen MR, Hollis JF, Senft RA. Screening and brief intervention for hazardous drinking in an HMO: effects on medical care utilization. Journal of Behavioural Health Services Research 2000; 27(4): 446-53.

20. Aalto M, Alho H, Halme JT, Seppä K. AUDIT and its abbreviated versions in detecting heavy and binge drinking in a general population survey. Drug and Alcohol Dependence 2009; 103(1-2): 25-9.

21. Parry CD, Plüddemann A, Steyn K, Bradshaw D, Norman R, Laubscher R. Alcohol use in South Africa: findings from the first Demographic and Health Survey (1998). Journal of Studies in Alcohol 2005; 66(1): 91-7.

22. World Health Organisation (WHO) Global status report on alcohol 2004. Geneva: WHO, 2004.

23. Miller JW, Gfroerer JC, Brewer RD, Naimi TS, Mokdad A, Giles WH. Prevalence of adult binge drinking: a comparison of two national surveys. American Journal of Preventive Medicine 2004; 27(3): 197-204.

24. Guo W, Lanzi G, Luobu O, Ma X, Zhen P, Ji Y, et al. An epidemiological survey of alcohol use disorders in a Tibetan population. Psychiatry Research 2008; 159(1-2): 56-66.25.

25. Giang KB, Allebeck P, Spak F, Van Minh H, Dzung TV. Alcohol use and alcohol consumption-related problems in rural Vietnam: an epidemiological survey using AUDIT. Substance Use and Misuse 2008; 43(3-4): 481-95.

26. Jirapramukpitak T, Prince $M$, Harpham T. Rural-urban migration, illicit drug use and hazardous/harmful drinking in the young Thai population. Addiction 2008; 103(1): 91-100.

27. Anderson P, Baumberg B. Alcohol in Europe. London: Institute of Alcohol Studies, 2006.

28. Bergman H, Källmén H. Alcohol use among Swedes and a psychometric evaluation of the alcohol use disorders identification test. Alcohol Alcohol 2002; 37(3): 245-51.

29. Clausen T, Rossow I, Naidoo N, Kowal P. Diverse alcohol drinking patterns in 20 African countries. Addiction 2009; 104(7): 1147-54.

30. Roerecke M, Obot IS, Patra J, Rehm J. Volume of alcohol consumption, patterns of drinking and burden of disease in sub-Saharan Africa, 2002. Afr J Drug Alcohol Studies 2008; 7(1):1-17.

31. Obot I Alcohol use and related problems in sub-Saharan Africa. African Journal of Drug and Alcohol Studies 2006; 5(1): 17-26.

32. Parry CGH, Bennets AL. Alcohol policy and public health in South Africa. New York: Oxford University Press, 1998.

33. Rahav G, Wilsnack R, Bloomfield K, Gmel G, Kuntsche S. The influence of societal level factors on men's and women's alcohol consumption and alcohol problems. Alcohol Alcohol Suppl 2006; 41 (1): i47-55.

34. Weiser SD, Leiter K, Heisler M, McFarland W, Percy-de Korte F, DeMonner SM, et al. A population-based study on alcohol and high-risk sexual behaviors in Botswana. PLoS Med 2006; 3(10): e392.

35. Stockwell T, Donath S, Cooper-Stanbury M, Chikritzhs T, Catalano P, Mateo C Under-reporting of alcohol consumption in household surveys: a comparison of quantity-frequency, graduated-frequency and recent recall. Addiction 2004; 99(8): 1024-33.

36. Parry CDH. South Africa: alcohol today. Addiction 2005; 100: 426-429.

37. Benegal V, Chand PK, Obot IS. Packages of care for alcohol use disorders in low- and middle-income countries. PLoS Med 2009; 6(10):e1000170.

38. Parry CDH. South Africa: alcohol today. Addiction 2005;100(4):426-9. 